Supporting Information for

\title{
Influence of Ions on the Size Dependent Morphology of Aerosol Particles
}

\author{
Emily-Jean E. Ott and Miriam Arak Freedman
}

Department of Chemistry, The Pennsylvania State University, University Park, Pennsylvania 16802

Number of Tables: 1

Number of Figures: 2

Number of Pages: 3

Summary: This document contains a comparison figure of a homogenous and a phase separated particle less than $30 \mathrm{~nm}$ in diameter, the experimental procedure for surface tension measurements with a table recording surface tensions for diethylmalonic acid with salts, and a histogram of particles composed of diethylmalonic acid and potassium sulfate. 


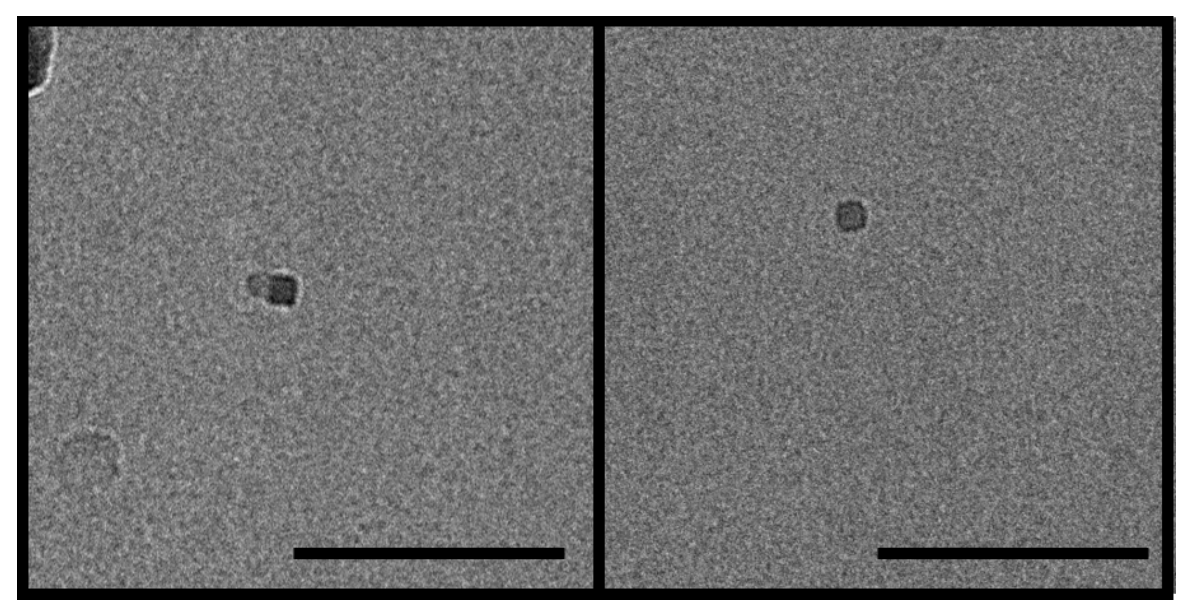

Figure S1: A comparison of particles composed of a mixture of diethylmalonic acid and sodium chloride with a) phase separated and b) homogeneous morphologies. Scale bars are $100 \mathrm{~nm}$. The approximate particle area equivalent diameters are $30 \mathrm{~nm}$.

\section{Surface Tension Experimental Procedure:}

The surface tension values were measured with a Krüss K11 tensiometer. The solutions measured contained $7.8 \mathrm{mmol}$ of salt and $5.0 \mathrm{mmol}$ of diethylmalonic acid. A typical optical microscopy experiment, as described in the experimental methods section for the collection of SRH values in the manuscript, uses $0.833 \mathrm{~g}$ of diethylmalonic acid, which corresponds to approximately $5.0 \mathrm{mmol}$, and $0.417 \mathrm{~g}$ of salt. This mass was converted to moles for each salt. The highest number of moles from that conversion was $7.8 \mathrm{mmol}$ which was chosen as representative for these measurements. These concentrations are equivalent to a relative humidity above $100 \%$. The reported values are the average and deviations for two solutions each of which were measured three times for a total of six values with each salt. 
Table S1: Surface tension data for diethylmalonic acid and salts with $7.8 \mathrm{mmol}$ of salt and 5.0 mmol of diethylmalonic acid in $25 \mathrm{~mL}$ water.

\begin{tabular}{|l|l|}
\hline & Diethylmalonic Acid \\
\hline Ammonium Sulfate & $49.5 \pm 0.3 \mathrm{dynes} / \mathrm{cm}$ \\
\hline Sodium Sulfate & $49.4 \pm 0.1 \mathrm{dynes} / \mathrm{cm}$ \\
\hline Ammonium Chloride & $48.0 \pm 0.4 \mathrm{dynes} / \mathrm{cm}$ \\
\hline Sodium Chloride & $46.6 \pm 0.7 \mathrm{dynes} / \mathrm{cm}$ \\
\hline
\end{tabular}

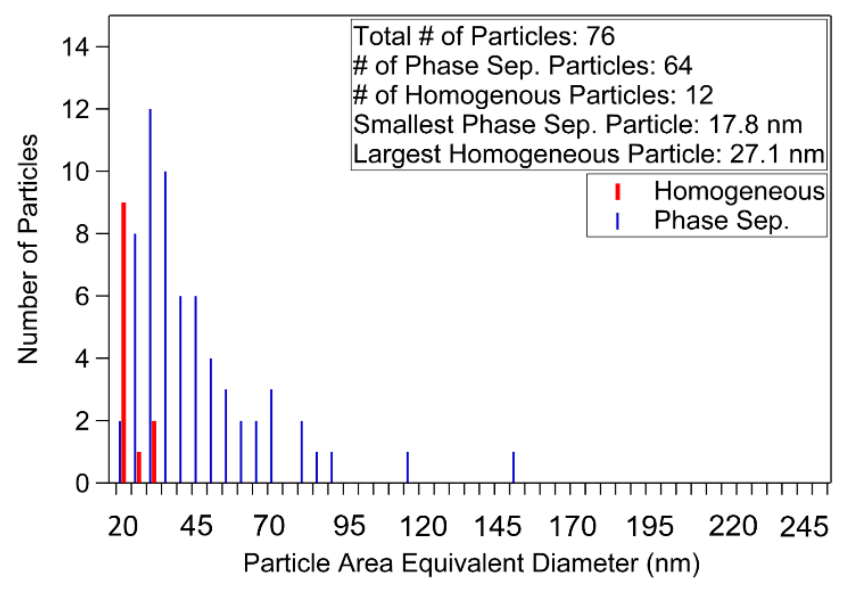

Figure S2: Histogram of diethylmalonic acid and potassium sulfate which is very similar to diethylmalonic acid and sodium sulfate. 